\title{
Extracellular Signal-Regulated Kinase 1/2 Is Required for the Induction of Group I Metabotropic Glutamate Receptor- Mediated Epileptiform Discharges
}

\author{
Wangfa Zhao, Riccardo Bianchi, Min Wang, and Robert K. S. Wong \\ Department of Physiology and Pharmacology, State University of New York Downstate Medical Center, Brooklyn, New York 11203
}

\begin{abstract}
Transient stimulation of group I metabotropic glutamate receptors (mGluRs) induces persistent prolonged epileptiform discharges in hippocampal slices via a protein synthesis-dependent process. At present, the signaling process underlying the induction of these epileptiform discharges remains unknown. We examined the possible role of extracellular signal-regulated kinases (ERK1 and ERK2) because these kinases can be activated by group I mGluRs, and their activation may regulate gene expression and alter protein synthesis. The group I mGluR agonist (S)-3,5-dihydroxyphenylglycine (DHPG; $50 \mu \mathrm{M}$ ) induced activation of ERK1/2 in hippocampal slices. 2-(2Diamino-3-methoxyphenyl-4H-1-benzopyran-4-one (PD98059) (50 $\mu \mathrm{M})$ a specific inhibitor of mitogen-activated protein kinase kinase (MEK), suppressed ERK1/2 activation by DHPG. PD98059 or another MEK inhibitor, 1,4-diamino-2,3-dicyano-1,4-bis[2aminophenylthio]butadiene $(10 \mu \mathrm{M})$, also prevented the induction of the prolonged epileptiform discharges by DHPG. In the presence of ionotropic glutamate receptor inhibitors and tetrodotoxin (blockers), DHPG-induced epileptiform discharges were suppressed, whereas ERK1/2 activation persisted. Protein kinase C inhibitors (2-[1-(3-dimethylaminopropyl)-5-methoxyindol-3-yl]-3-(1H-indol-3-yl) maleimide, $1 \mu \mathrm{M}$; or chelerythrine, $10 \mu \mathrm{M}$ ) did not prevent the generation of DHPG-induced epileptiform discharges, nor did they suppress the activation of ERK1/2 by DHPG in slices pretreated with the blockers. Genistein $(30 \mu \mathrm{M})$, a broad-spectrum tyrosine kinase inhibitor, suppressed the DHPG-induced epileptiform discharges and the ERK1/2 activation in the presence of blockers. Induction of DHPGmediated epileptiform discharges was also suppressed by 4-amino-5-(4-chlorophenyl)-7-(t-butyl)pyrazolo[3,4-D]pyrimidine (10 $\mu \mathrm{M})$, an Src-family tyrosine kinase inhibitor. The study shows that group I mGluRs activate ERK1/2 through a tyrosine kinase-dependent process and that this activation of ERK1/2 is necessary for the induction of prolonged epileptiform discharges in the hippocampus.
\end{abstract}

Key words: ERK1/2; metabotropic glutamate receptor; DHPG; tyrosine kinase; PKC; hippocampus

\section{Introduction}

Mitogen-activated protein kinases (MAPKs) are a group of Ser/ Thr-kinases that play pivotal roles in the control of gene expression, cell proliferation, and differentiation (Chang and Karin, 2001). Activated MAPKs phosphorylate a wide range of protein substrates, including membrane-bound, nuclear, and signaling proteins (Grewal et al., 1999). In mammalian cells, one subgroup of MAPKs, the extracellular signal-regulated kinase 1/2 (ERK1/ 2 ), is involved in cell growth, proliferation, and differentiation (Pearson et al., 2001) through regulation of gene expression and protein synthesis (Lin et al., 1994; Hazzalin and Mahadevan, 2002).

The signaling mechanisms underlying receptor tyrosine kinase (RTK)-mediated ERK1/2 activation have been extensively studied. The RTKs include growth factor receptors such as epi-

\footnotetext{
Received June 26, 2003; revised Nov. 3, 2003; accepted Nov. 4, 2003.

This work was supported by National Institute of Neurological Disorders and Stroke Grant NS-35481. We thank Todd Sacktor and John Crary for helpful discussion.

Correspondence should be addressed to Dr. Robert K. S. Wong, Department of Physiology and Pharmacology, Box 29, State University of New York Downstate Medical Center, 450 Clarkson Avenue, Brooklyn, NY 11203. E-mail: bwong@downstate.edu.

DOI:10.1523/JNEUROSCI.4515-03.2004

Copyright $\odot 2004$ Society for Neuroscience $\quad$ 0270-6474/04/230076-08\$15.00/0
}

dermal growth factor and platelet-derived growth factor receptors (Johnson and Vaillancourt, 1994; Weiss et al., 1997). Interestingly, recent studies reveal that G-protein-coupled receptors (GPCRs) also activate the ERK1/2 cascade (Gutkind, 2000). The signaling mechanisms coupling GPCRs to ERK1/2 are rich and diverse. Transactivation can result from the downstream actions of $\mathrm{G} \alpha$-protein or $\mathrm{G} \beta \gamma$-protein subunits. In cell-expression systems and peripheral tissue, GPCR stimulation can elicit cell growth (Post and Brown, 1996) and malignant cell proliferation (Young et al., 1986; Gutkind et al., 1991).

In the CNS, metabotropic glutamate receptors (mGluRs), a group of GPCRs activated by glutamate, play a role in synaptic plasticity (Bortolotto et al., 1994; Anwyl, 1999; Huber et al., 2000; Watabe et al., 2002). Recent data reveal that mGluRs regulate protein synthesis (Weiler and Greenough, 1993) via translation processes (Huber et al., 2000; Raymond et al., 2000) to bring about long-term modifications of synaptic transmission. A role of ERK1/2 has been proposed in the induction of some forms of these modifications (Roberson et al., 1999).

Endogenous activation of group I mGluRs, a subgroup of mGluRs coupled to the $\mathrm{G} \alpha_{\mathrm{q} / 11}$ protein (Masu et al., 1991; Abe et al., 1992), has been shown to contribute to epileptiform burst activity in hippocampal neurons (Lee et al., 2002) and to regulate 
the excitability of neocortical neurons (Bandrowski et al., 2003). We showed that stimulation of group I mGluRs induces prolonged synchronized discharges in hippocampal slices (Taylor et al., 1995). These prolonged discharges resemble ictal discharges in epilepsy and have two distinct properties: (1) The "prolonged epileptiform discharges," once induced by group I mGluR agonists, are maintained for hours after agonist washout (Merlin and Wong, 1997). (2) Induction of the prolonged epileptiform discharges is prevented in hippocampal slices in which protein synthesis is blocked by anisomycin or cycloheximide (Merlin et al., 1998). These data suggest that group I mGluR stimulation elicits epileptogenesis in hippocampal slices through a protein synthesis-dependent process.

At present, the signaling process underlying the group I mGluR-induced epileptogenesis is largely unknown. Because of the available evidence indicating the activation of ERK1/2 by group I mGluRs (Peavy and Conn, 1998; Ferraguti et al., 1999; Roberson et al., 1999; Berkeley and Levey, 2003) and the downstream action of ERK1/2 in altering protein synthesis, we performed experiments to test whether activation of the ERK1/2 cascade is necessary for group I mGluR-induced epileptogenesis.

\section{Materials and Methods}

Slice preparation and electrophysiology. Four- to 6-week-old mice were used (B6/129PLC $\beta$ colony; State University of New York Downstate Medical Center, Brooklyn, NY). Transverse hippocampal slices (400 $\mu \mathrm{m}$ thick) were prepared as described previously (Chuang et al., 2002). During slicing, the hippocampi were submerged in an ice-cold low-Ca ${ }^{2+}$ / high- $\mathrm{Mg}^{2+}$ buffer, consisting of the following (in $\mathrm{mM}$ ): $124 \mathrm{NaCl}, 26$ $\mathrm{NaHCO}_{3}, 2.5 \mathrm{KCl}, 8 \mathrm{MgCl}_{2}, 0.5 \mathrm{CaCl}_{2}$, and $10 \mathrm{D}$-glucose bubbled with $95 \% \mathrm{O}_{2}$ and $5 \% \mathrm{CO}_{2}$. Slices were transferred to an interface chamber (Fine Science Tools, Foster City, CA) perfused with normal solution [artificial CSF (ACSF)] consisting of the following (in mM): $124 \mathrm{NaCl}, 26$ $\mathrm{NaHCO}_{3}, 5 \mathrm{KCl}, 1.6 \mathrm{MgCl}_{2}, 2 \mathrm{CaCl}_{2}$, and 10 D-glucose bubbled with $95 \%$ $\mathrm{O}_{2}$ and $5 \% \mathrm{CO}_{2}$. Slices were maintained at $34.5^{\circ} \mathrm{C}$ in an interface chamber for at least $60 \mathrm{~min}$ before electrophysiological recording. For Western blot experiments in Figures 1 and 2, slices were maintained in adjacent wells of the interface chamber and were collected after electrophysiological recordings as stated in Results. For Western blot experiments in other figures, slices were maintained at $31^{\circ} \mathrm{C}$ in a slice holding chamber (Harvard Apparatus, Holliston, MA) for at least $90 \mathrm{~min}$ before drug application.

Microelectrodes were pulled from glass tubes $(1 \mathrm{~mm}$ outer diameter with glass filament inside, World Precision Instruments, Sarasota, FL) using a micropipette puller (Sutter Instruments, Novato, CA). Microelectrodes were filled with $2 \mathrm{M}$ potassium acetate and the resistances were $\sim 70 \mathrm{M} \Omega$. Signals were amplified (Axoclamp 2B; Axon Instruments, Union City, CA) and recorded simultaneously in a computer running pClamp6 (Axon Instruments) and on a chart recorder (Gould, Valley View, $\mathrm{OH})$.

Drugs. Pharmacological agents were delivered to the hippocampal slices through continuous perfusion. Depending on the flow rate, the final concentration was reached within $15 \mathrm{~min}$. For Western blot experiments using a slice-holding chamber, agents were applied to the chamber directly. Pretreatment of slices with inhibitors (see Results) lasted for 45 min. 6-Cyano-7-nitroquinoxaline-2,3-dione (CNQX), 3-(+-2carboxypiperazin-4-yl)-propyl-1-phosphonic acid (CPP), (S)-3,5dihydroxyphenylglycine (DHPG), 4-amino-5-(4-chlorophenyl-7-(tbutyl)pyrazolo[3,4-D]pyrimidine (PP2), chelerythrine chloride, and 1-4diamino-2,3-dicyano-1,4-bis[2-aminophenylthio]butadiene (U0126) were purchased from Tocris (Ellisville, MO). Genistein, genistin, 2-[1(3-dimethylaminopropyl)-5-methoxyindol-3-yl]-3-(1H-indol-3-yl) maleimide (Gö6983), and 2-(2-amino-3-methoxyphenyl)-4H-1-benzopyran-4-one (PD98059) were from Calbiochem (La Jolla, CA). Antibodies for total and phospho-ERK1/2 were from Cell Signaling Technology (Beverly, MA). The other chemicals were from Sigma (St. Louis, MO). PD98059, genistein, genistin, Gö6983, PP2, and U0126 were prepared in
DMSO stock solutions. Before drug application, stock solutions were diluted 500 (0.2\% DMSO) or 1000 (0.1\% DMSO) times in normal ACSF with strong agitation to ensure complete solubility. In control experiments, $0.2 \%$ DMSO vehicle perfusion did not affect DHPG-induced responses. In addition, DHPG-induced epileptiform bursts recorded in slices perfused with $0.2 \%$ DMSO (for dissolving Gö6983) (see Fig. 3B,C) were indistinguishable from those recorded in ACSF (see Fig. 1A,B)

Sample preparation. For electrophysiological recording experiments, slices were removed from the interface chamber and frozen immediately on dry ice. For time-course studies, slices were collected at 0, 5, 20, and 90 min after drug treatment from the slice-holding chamber and frozen immediately on dry ice. Each sample containing four to six slices was stored at $-80^{\circ} \mathrm{C}$ until biochemical analysis.

Samples were homogenized with a motor-driven tissue grinder (15 strokes, 1 sec per stroke; pellet pestle; VWR Scientific, West Chester, PA) in an appropriate volume of ice-cold homogenization buffer containing the following (in mM): 50 Tris- $\mathrm{HCl}, \mathrm{pH} 7.5,1$ EGTA, 1 EDTA and protease inhibitors [0.1 aprotinin, 0.1 leupeptin, $0.14-2$ (-aminoethyl) benzenesulfonyl fluoride, 5 benzamidine, and $5 \beta$-mercaptoethanol (BME)] and phosphatase inhibitors (4 4-nitrophenyl phosphate; 2 sodium pyrophosphate, and 1 sodium orthovanadate). The homogenate was then centrifuged at $12,000 \times g$ for $10 \mathrm{~min}$ at $4^{\circ} \mathrm{C}$ to remove debris. The supernatant was transferred to a clean, prechilled centrifuge tube. One aliquot was used for Bradford Assay (Bio-Rad Laboratories, Hercules, CA) to determine protein concentration. $5 \times$ SDS sample buffer (50\% glycerol, 25\% BME, and 12\% SDS, in $310 \mathrm{~mm}$ Tris-HCl, pH 6.8) was immediately added to the rest of the supernatant. Samples were boiled for $5 \mathrm{~min}$ and stored for future use.

Western blot. Equal sample amounts ( $10 \mu \mathrm{g}$ per lane) were subjected to electrophoresis in $8 \%$ SDS-PAGE gels (1.5 mm Novex Tris-Glycine; Invitrogen, Carlsbad, CA). Gels were then transferred to nitrocellulose membranes for $2.5 \mathrm{hr}$ at a constant voltage of $25 \mathrm{~V}$ (Novex Mini-Cell; Invitrogen). The membrane was stained with Ponceau $S$ briefly to verify the quality of transfer. The membrane was blocked in 5\% nonfat milk dissolved in TBS-Tween 20 (TBST) buffer (containing the following: 20 mu Tris- $\mathrm{HCl}, \mathrm{pH} 7.6,15 \mathrm{~mm} \mathrm{NaCl}$, and $0.1 \%$ Tween 20 ) for $1 \mathrm{hr}$ at room temperature or overnight at $4^{\circ} \mathrm{C}$. After blocking, the membrane was probed with primary antibody (phospho-ERK1/2 (Thr202/Tyr204) antibody (rabbit polyclonal IgG); 1:1000 diluted in 5\% nonfat milk; Cell Signaling Technology) for $2 \mathrm{hr}$ at room temperature or overnight at $4^{\circ} \mathrm{C}$. After incubation, the membrane was washed three times for 5 min each with TBST. The membrane was then incubated with HRP-conjugated anti-rabbit secondary antibody in TBST (1:2000, Cell Signaling Technology) for $1 \mathrm{hr}$. The membrane was washed again three times for $5 \mathrm{~min}$ each with TBST. Then the membrane was treated with LumiGLO (Cell Signaling Technology) and developed. To determine the total amount of ERK1/2, the membrane was stripped in stripping buffer $(62.5 \mathrm{~mm}$ Tris$\mathrm{HCl}, \mathrm{pH} 6.8,100 \mathrm{~mm} \mathrm{BME}, 2 \% \mathrm{SDS}$ ) for $1 \mathrm{hr}$ at $60^{\circ} \mathrm{C}$ and washed twice 10 min each with TBST and reblocked as above. The membrane was reprobed with an ERK1/2 antibody (rabbit polyclonal $\operatorname{IgG}, 1: 1000$ diluted in 5\% nonfat milk; Cell Signaling Technology). The rest of the procedure was the same as that for phospho-ERK1/2 antibody.

Data analysis. The duration of an individual epileptiform burst was measured from the beginning of the first action potential of the burst to the repolarization of the last action potential of the burst. Burst durations of all epileptiform bursts in a 5 min period for each slice in the various experimental conditions were averaged. Epileptiform bursts with a duration longer than $1.5 \mathrm{sec}$ are referred to as prolonged epileptiform discharges. The anti-phosphorylated-ERK1/2 (Thr202/Tyr204) and antiERK1/2 immunoreactive bands of the same gel were scanned with a desktop scanner (UMAX, Dallas, TX) and quantified with Scion Image software (Scion Image, Frederick, MD). The optical densities (ODs) of anti-phospho-ERK1/2 (Thr202/Tyr204) bands were normalized to the OD value of their own anti-ERK1/2 bands.

Summary data are reported as means \pm SEM. Student's $t$ test was used for the statistical comparison of two sets of data. For analysis of time course data (see Figs. 3A, 5), one-way ANOVA followed by the NewmanKeuls test for repeated measures was applied. In all cases, the level of significant difference was $p<0.05$. 


\section{Results}

Stimulation of group I mGluRs induces prolonged

epileptiform discharges in hippocampal slices

Intracellular recordings were obtained in CA3 pyramidal cells. DHPG $(50 \mu \mathrm{M})$, a group I mGluR agonist, elicited neuronal depolarization and clusters of synaptic depolarizations (Fig. 1 $A b$ ). Rhythmic short (120-800 msec) epileptiform bursts then appeared (Fig. $1 A c$ ), and their frequency gradually increased with DHPG perfusion (from $\sim 0.05$ to $0.27 \mathrm{~Hz}$ ). Epileptiform activities were distinguished from spontaneous single cell spiking activities in that epileptiform activities persisted with membrane hyperpolarization and their frequencies were not affected by changes in membrane potential (data not shown). Recordings were generally performed at hyperpolarized levels $(-70 \mathrm{mV}$ or more) to selectively record epileptiform activities. In all of the experiments reported here, epileptiform bursts were not observed before the addition of DHPG.

In 20 of 23 slices recorded in DHPG, within 10 min of the occurrence of short epileptiform bursts, prolonged epileptiform discharges (duration, $5.1 \pm 0.4 \mathrm{sec} ; n=20$ ) (Fig. $1 A d, B a$ ) appeared abruptly. In the remaining slices, prolonged epileptiform discharges emerged more gradually and with longer and more variable delays. In all cases reported here, activation of short epileptiform bursts by DHPG was always followed by the occurrence of prolonged epileptiform discharges.

When prolonged epileptiform discharges first appeared, they coexisted with the short epileptiform bursts. With continued DHPG exposure, prolonged epileptiform discharges gradually dominated and eventually the rhythm of the population events was determined mainly by the occurrence of prolonged epileptiform discharges (Fig. 1 $A d, f, B a$ ). For any given preparation, the duration of epileptiform activities elicited by DHPG fell into two distinct, nonoverlapping groups (Fig. $1 A f, B a$ ). The mean durations of epileptiform bursts recorded in all slices $(n=20)$ after $15 \mathrm{~min}$ and after 25 min of DHPG perfusion were plotted in Figure $1 \mathrm{Bb}$. Because of the occurrence of prolonged epileptiform bursts at $25 \mathrm{~min}$ after DHPG perfusion, the mean duration of epileptiform bursts was significantly longer than that measured at $15 \mathrm{~min}$.

\section{ERK1/2 phosphorylation is necessary for the induction of} prolonged epileptiform discharges

The effect of DHPG perfusion on ERK1/2 activation was examined using Western blots. Slices were placed in the interface recording chamber, and after $\sim 1 \mathrm{hr}$ of perfusion with control solution, four to six slices were collected for Western blot analysis of ERK1/2 phosphorylation. Remaining slices in the chamber were then exposed to DHPG, and intracellular recordings were performed to monitor the neuronal activities. Approximately $1 \mathrm{hr}$ after the appearance of prolonged epileptiform discharges, additional slices were collected for Western blot analysis. Figure $1 C$ shows that, after the exposure to DHPG and the elicitation of prolonged epileptiform discharges, ERK1/2 phosphorylation increased significantly ( $300 \pm 54 \%$ of control; $n=6 ; p<0.01$ ) (Fig. $1 C b)$.

A specific MEK inhibitor, PD98059, was used to examine the role of ERK1/2 phosphorylation in epileptiform discharges. Hippocampal slices were pretreated with PD98059 $(50 \mu \mathrm{M})$ for 45 min before exposure to DHPG. Under this condition, the perfusion of slices with DHPG elicited short epileptiform bursts (Fig. $2 \mathrm{Aa}$ ). With continued perfusion, the frequency of the short epileptiform bursts increased as in the control condition without PD98059 treatment (Fig. 2Ab). However, unlike events observed under the control condition, the emergence of short epileptiform
A
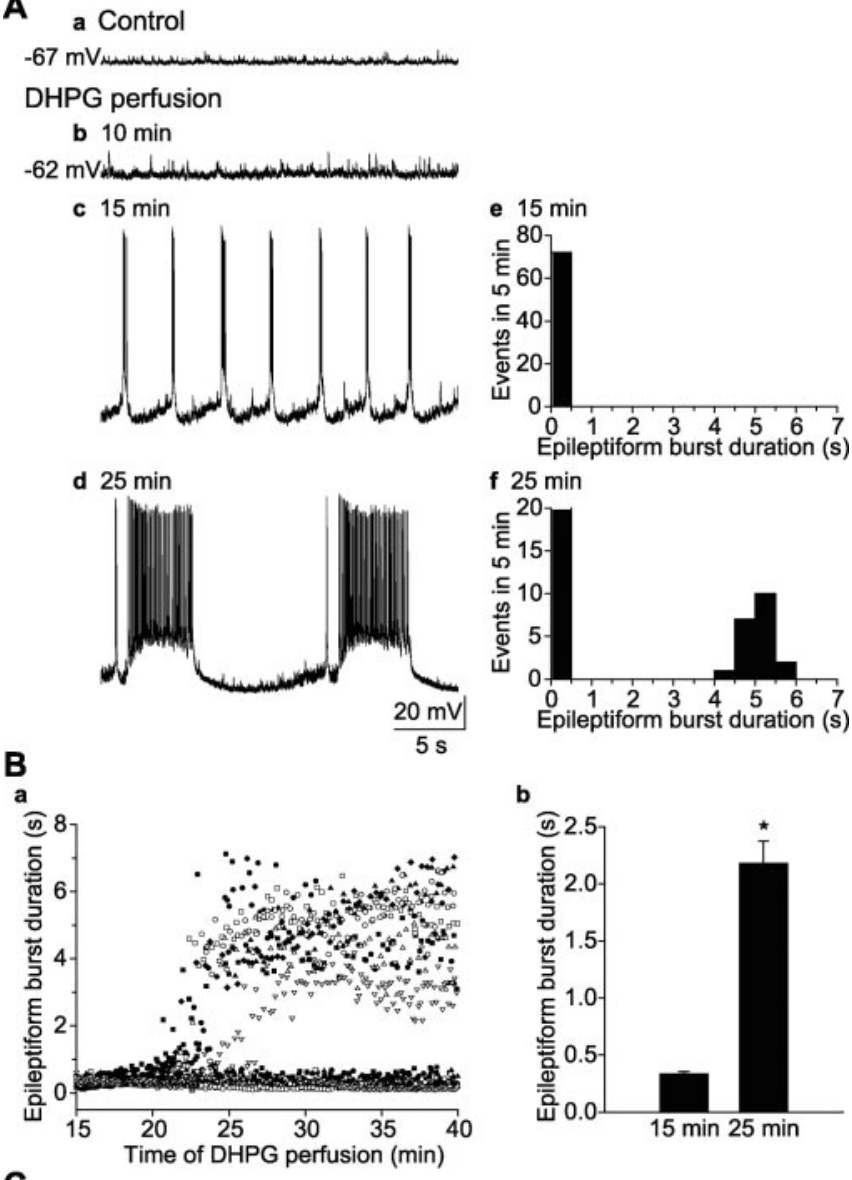

f $25 \mathrm{~min}$

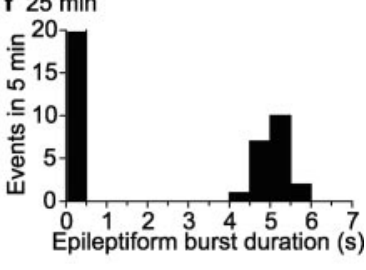

b

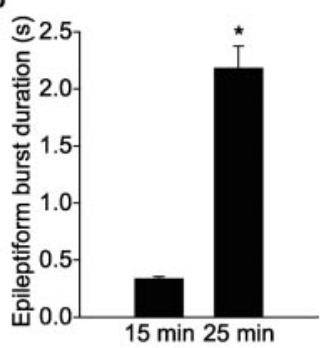

a

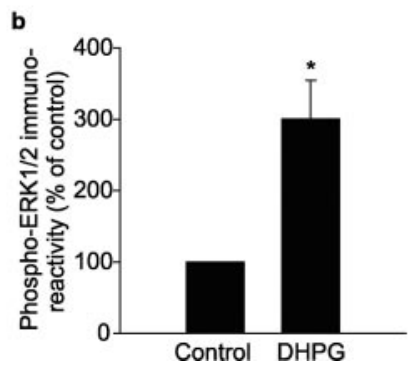

Figure 1. DHPG-induced prolonged epileptiform discharge in hippocampal slices is associated with an increase in the phosphorylation of ERK1/2.Aa- $d$, Intracellular recordings from the same CA3 pyramidal cell. Ab, DHPG $(50 \mu \mathrm{m})$ caused neuronal depolarization and the appearance of clusters of synaptic depolarizations. $A c$, Rhythmic short epileptiform bursts $(120-800 \mathrm{msec})$ were observed $15 \mathrm{~min}$ after the application of DHPG. Ad, Within $10 \mathrm{~min}$ after the appearance of short epileptiform bursts, prolonged epileptiform discharges appeared abruptly. Ae, $f$, Frequency histograms of epileptiform burst duration measured from records of the same cell shown in $a-d$ during the $15-20 \mathrm{~min}(e)$ and 25-30 min (f) periods of DHPG perfusion. Epileptiform bursts elicited by DHPG fell into two distinct, nonoverlapping groups. $B a$, Time course of the epileptiform burst duration in eight different slices recorded 15-40 min after switching perfusion to a DHPG-containing solution. Different symbols represent different experiments. Open circles are measures from the experiment shown in $A . B b$, Mean \pm SEM of epileptiform burst durations averaged over 5 min periods starting at $15 \mathrm{~min}$ (left bar) and at 25 min (right bar) of DHPG perfusion in 20 different experiments. Mean burst duration was $0.335 \pm 0.021$ sec at $15 \mathrm{~min}$ and significantly increased to $2.180 \pm 0.194 \mathrm{sec}$ at $25 \mathrm{~min}\left({ }^{*} p<0.001\right)$ because of the appearance of prolonged epileptiform discharges. Ca, Representative Western blots of samples obtained from slices expressing prolonged epileptiform discharges (including the slice whose recordings are shown in $A$ ) after $1 \mathrm{hr}$ of DHPG perfusion. Top, Anti-phospho-ERK1/2 blot; bottom, anti-total ERK1/2 blot. In each panel, the top band is p44 MAPK (ERK1) and the bottom band is p42 MAPK (ERK2). Western blots are presented in the same manner in the following figures. $B b$, Summary data of normalized phospho-ERK1/2 immunoreactivity. The ratio of phospho-ERK1/2 to total-ERK1/2 immunoreactivity was normalized to the control value. After the elicitation of prolonged epileptiform discharges, ERK1/2 phosphorylation increased significantly (DHPG, $300 \pm 54 \% ; n=6$; ${ }^{*} p<0.01$ compared with the control). 
A
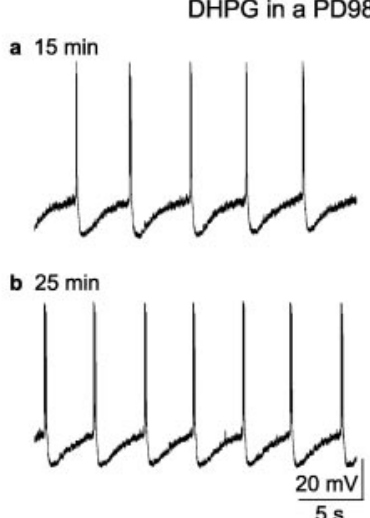

B

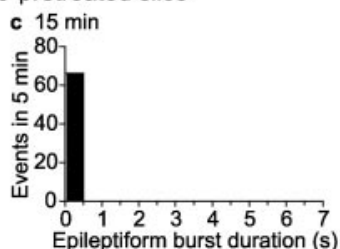

d $25 \mathrm{~min}$

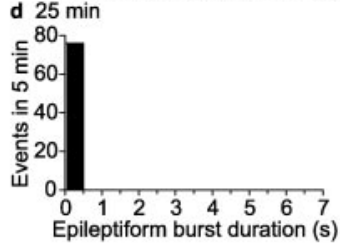
pretreated slices

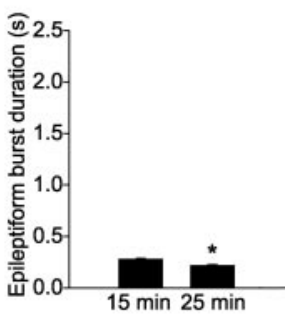

C

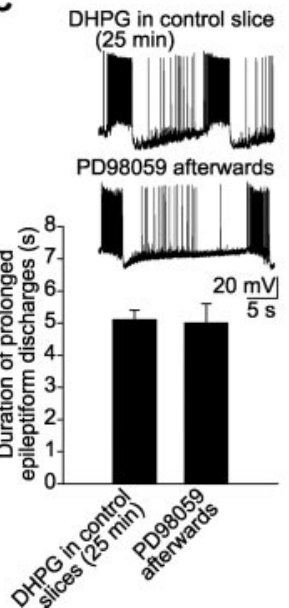

D

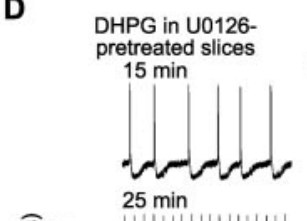

E

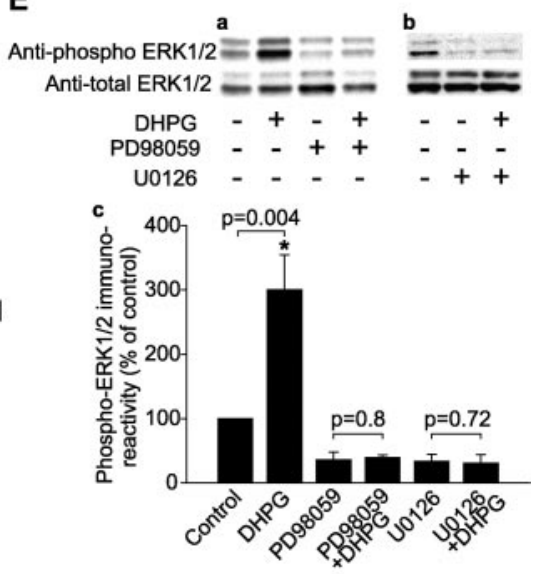

Figure 2. MEK inhibitors block the DHPG-induced ERK1/2 phosphorylation and the induction of prolonged epileptiform discharges. A, In a slice pretreated with PD98059 (50 $\mu \mathrm{m} ; 45 \mathrm{~min}$ ), DHPG induced short epileptiform bursts but not prolonged epileptiform discharges. In five experiments, the frequency of the short epileptiform bursts increased from $0.15 \pm 0.03 \mathrm{~Hz}$ at 15 min of DHPG to $0.39 \pm 0.10 \mathrm{~Hz}$ at $25 \mathrm{~min}$ of DHPG $(p<0.05)$. B, The mean burst duration at $25 \mathrm{~min}$ of DHPG perfusion $(0.214 \pm$ $0.010 \mathrm{sec})$ was significantly shorter than that at $15 \mathrm{~min}\left(0.273 \pm 0.014 \mathrm{sec} ; n=5 ;{ }^{*} p<0.001\right)$. Compared with the control condition, PD98059 did not affect burst duration at $15 \mathrm{~min}$ of DHPG $(p=0.16)$. C, Records from a representative CA3 pyramidal cell after 25 min of DHPG perfusion (top) and 30 min after addition of PD98059 to the perfusate (bottom). The mean duration \pm SEM of prolonged epileptiform discharges in four experiments (histogram) shows that PD98059 applied after the appearance of prolonged epileptiform discharges (i.e., epileptiform bursts $>1.5 \mathrm{sec}$ ) did not affect the occurrence of the events ( $25 \mathrm{~min}$ DHPG, $5.1 \pm 0.3 \mathrm{sec} ; 30 \mathrm{~min}$ after PD98059 addition, $5.0 \pm 0.6 \mathrm{sec} ; p=0.77$ ). $D$, Records from one (A3 neuron (top) and average duration from three experiments (histogram) of epileptiform bursts induced by DHPG in slices pretreated with another MEK inhibitor, U0126 (10 $\mu \mathrm{m} ; 45 \mathrm{~min})$. Like PD98059, U0126 prevented the induction of prolonged epileptiform discharges, decreased the duration of the short epileptiform bursts ( $15 \mathrm{~min}, 0.274 \pm 0.045 \mathrm{sec} ; 25 \mathrm{~min}, 0.179 \pm 0.039 \mathrm{sec} ;{ }^{*} p<0.05$ ), and increased the frequency of the short epileptiform bursts (at $15 \mathrm{~min}, 0.12 \pm 0.06 \mathrm{~Hz}$; at $25 \mathrm{~min}, 0.38 \pm 0.10 \mathrm{~Hz} ; p<0.05$ ). Ea, $b$, Representative Western blots of slices recorded under the indicated conditions (including the slices whose recordings are shown in $A$ and $D$ ). Ec, Summary data of normalized phospho-ERK1/2 immunoreactivity under the conditions indicated in $E a, b$. Measures of the ERK1/2 phosphorylation rise by DHPG in the control condition are from Figure 1. PD98059 and U0126 significantly decreased ERK1/2 basal level ( $p<0.01$ and $p<0.05$ compared with control, respectively) and blocked the DHPG-induced ERK1/2 phosphorylation (PD98059, $36 \pm 12 \%$ of control; PD98059+DHPG, $39 \pm 4 \% ; n=6 ; p=0.8$; U0126, $33 \pm 11 \%$; $\mathrm{U} 0126+\mathrm{DHPG}, 30 \pm 14 \% ; n=3 ; p=0.72$ ).

bursts was not followed by the appearance of prolonged epileptiform discharges (Fig. $2 A d$ ). Because of the absence of prolonged epileptiform discharges, the mean burst duration measured at 25 min was not longer than that obtained at 15 min after DHPG perfusion $(n=5)$ (Fig. $2 B$ ). In fact, the burst duration became shorter because of the independent action of DHPG on accelerating the short epileptiform bursts, as observed under the control condition (see above; see also Merlin et al., 1998).

When PD98059 was applied after prolonged epileptiform discharges were already elicited by DHPG, the MEK inhibitor did not affect the occurrence of ongoing events (duration: before
DHPG in PD98059

PD98059, $5.1 \pm 0.3 \mathrm{sec}$; after PD98059, $5.0 \pm 0.6 \mathrm{sec} ; n=4 ; p=0.77$ ) (Fig. $2 C$ ). The results suggest that although ERK1/2 activation is necessary for the initiation of prolonged epileptiform discharges, ERK1/2 activation is not required for the maintenance of the discharges.

Results obtained with PD98059 were supplemented by using another MEK inhibitor, U0126 (10 $\mu \mathrm{M})$, observed by other investigators to be effective in suppressing ERK1/2 activation in hippocampal slices (Roberson et al., 1999). Figure 2D shows that after the pretreatment of slices with U0126 (10 $\mu \mathrm{M} ; 45 \mathrm{~min})$ DHPG elicited short epileptiform bursts but not prolonged epileptiform discharges.

Western blot analysis showed that PD98059 suppressed the basal level of ERK1/2 phosphorylation by $64 \%$ (Fig. $2 \mathrm{Ea}, \mathrm{c}$ ). In addition, pretreatment of slices with PD98059 prevented the increase in ERK1/2 phosphorylation by DHPG (PD98059, $36 \pm 12 \%$ of control, $n=6$; PD98059 plus DHPG, $39 \pm 4 \%$ of control, $n=6 ; p=0.8$ ) (Fig. $2 E c$ ). Similar effects of U0126 on ERK1/2 phosphorylation were also observed (Fig. $2 E b, c$ ).

Stimulation of group I mGluRs directly activates ERK1/2

Group I mGluR-induced ERK1/2 activation can result from (1) the intense neuronal firing and the resulting $\mathrm{Ca}^{2+}$ entry through activated ionotropic glutamate receptors (English and Sweatt, 1996) and voltage-gated $\mathrm{Ca}^{2+}$ channels (Bading et al., 1993) or (2) the action of intracellular signals turned on by group I mGluR stimulation (Peavy and Conn, 1998; Roberson et al., 1999). To distinguish between the different modes of ERK1/2 activation, we pretreated slices with NMDA and nonNMDA receptor inhibitors (CPP and CNQX; $20 \mu \mathrm{M}$ each) and tetrodotoxin (TTX; $0.3 \mu \mathrm{M}$ ) to suppress neuronal firing and reduce the activation of voltage-gated $\mathrm{Ca}^{2+}$ channels. DHPG was applied after the pretreatment with and in the presence of these blockers. ERK1/2 phosphorylation was examined under this condition. Figure $3 A$ shows that ERK1/2 phosphorylation was stimulated by DHPG in the presence of the blockers. ERK1/2 phosphorylation peaked (at 5 min in DHPG, $167 \pm 12 \%$ of control; $n=8$; $p<0.01$ ) within 20 min after DHPG application. Phosphorylation activity declined to baseline (112 $\pm 7 \%$ of control; $n=8 ; p=0.12$ ) at 90 min after continuous DHPG perfusion.

Tyrosine kinase activation links group I mGluR stimulation to ERK1/2 phosphorylation

After G-protein-coupled receptor activation, the protein kinase $\mathrm{C}(\mathrm{PKC})$ - and tyrosine kinase-dependent pathways are two major 
signaling processes leading to ERK1/2 activation (Gutkind, 2000). Previous studies in hippocampal slices have shown that PKC activation is involved in the phosphorylation of ERK1/2 by group I mGluRs (Roberson et al., 1999). We examined whether PKC signaling is also involved in mediating the ERK1/2 activation underlying the generation of prolonged epileptiform discharges.

In the presence of Gö6983 (1 $\mu \mathrm{M})$, a PKC inhibitor (Gschwendt et al., 1996), DHPG added to the perfusing solution elicited short epileptiform bursts and prolonged epileptiform discharges (Fig. 3B). The duration of the prolonged epileptiform discharges recorded in the presence of Gö6983 was not significantly different from that observed in control experiments (in control, $5.1 \pm 0.4 \mathrm{sec}, n=20$; in Gö6983, $4.8 \pm 0.8 \mathrm{sec}, n=4 ; p>0.05)$. Because of the presence of prolonged epileptiform bursts after $25 \mathrm{~min}$ of DHPG perfusion, the mean duration of all epileptiform bursts measured at $25 \mathrm{~min}$ was significantly longer than that recorded at 15 $\min$ (Fig. 3C).

To examine the effects of Gö6983 on ERK1/2 activation, slices were incubated in Gö6983 ( $1 \mu \mathrm{M} ; 45 \mathrm{~min}$ ) in the presence of CNQX, CPP, and TTX (blockers), before addition of DHPG. After DHPG treatment for $5 \mathrm{~min}$, slices were harvested for Western blot analysis. ERK1/2 phosphorylation by DHPG persisted in the presence of Gö6983 (in blockers, $167 \pm 12 \%, n=8$; in blockers plus Gö6983, $166 \pm 9 \%, n=5$; $p=0.94)$ (Fig. 3D). The data suggest that the signaling cascade for group I mGluRinduced ERK1/2 phosphorylation and prolonged epileptiform discharges is independent of PKC activation.

Figure $3 E$ shows that pretreatment of slices for $45 \mathrm{~min}$ with chelerythrine (10 $\mu \mathrm{M})$, another broad-spectrum PKC inhibitor, also did not prevent the induction of the prolonged epileptiform discharges by DHPG $(n=5)$ (see also Chen et al., 1998).

An alternative common transduction pathway for ERK1/2 phosphorylation is via tyrosine kinases (Gutkind, 2000). We studied the effects of the broad-spectrum tyrosine kinase inhibitor, genistein (Akiyama et al., 1987), on the DHPG-elicited responses. Slices were perfused with genistein $(30 \mu \mathrm{M})$ for $45 \mathrm{~min}$ before agonist application. Under this condition DHPG elicited short epileptiform bursts accelerating as in control condition without genistein pretreatment, but prolonged epileptiform discharges were no longer observed $(n=$ 8) (Fig. $4 A$ ). In another set of experiments $(n=6)$, genistein, applied after the appearance of the DHPG-induced prolonged epileptiform discharges, did not affect the occurrence of these events (duration: before genistein, $4.4 \pm 0.4 \mathrm{sec}$; after genistein, $3.8 \pm 0.6 \mathrm{sec} ; n=6$; $p=0.25)($ Fig. $4 B)$.

We tested the specificity of the action of genistein using its analog genistin, which is inactive against tyrosine kinase (Hamakawa et al.,
1999). After the pretreatment of slices with genistin ( $30 \mu \mathrm{M} ; 45 \mathrm{~min})$, DHPG perfusion elicited short epileptiform bursts followed by the timely appearance of prolonged epileptiform discharges. A plot of epileptiform burst mean durations elicited after genistin pretreatment by DHPG at 15 and $25 \mathrm{~min}(n=4)$ (Fig. $4 C)$ shows that the mean duration was significantly longer at 25 than at 15 min because of the emergence of prolonged epileptiform discharges.

To further define the type of tyrosine kinase involved in the regulation of ERK1/2 phosphorylation by group I mGluR activation, we evaluated the action of PP2, an inhibitor of the Srcfamily tyrosine kinases (see also Zhao et al., 2003). After pretreatment with PP2 (10 $\mu \mathrm{M} ; 45 \mathrm{~min})$, DHPG was introduced to the slice-perfusing solution. In three experiments, short epileptiform bursts were elicited, but these were not followed by prolonged epileptiform discharges (Fig. 4D). The average burst duration at $25 \mathrm{~min}$ did not increase over that measured after 15 min of DHPG exposure. Again, the epileptiform burst duration became significantly shorter because of the increase in burst frequency. On average, there was no 
A

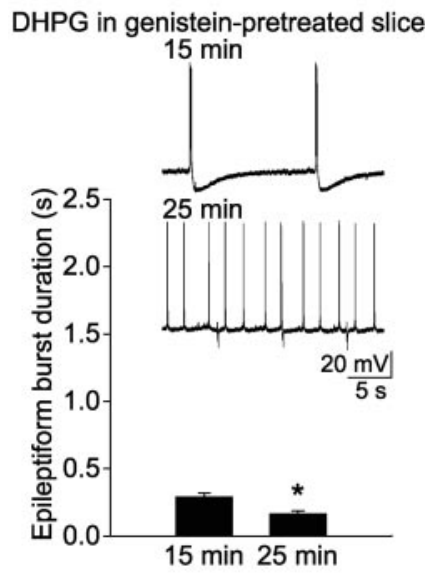

C

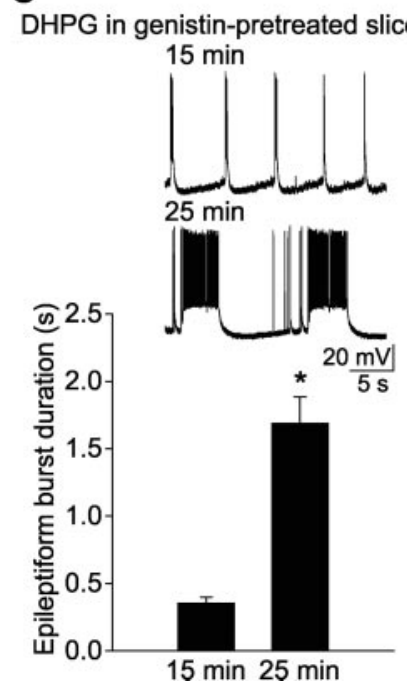

B

DHPG in control slice (25 min)
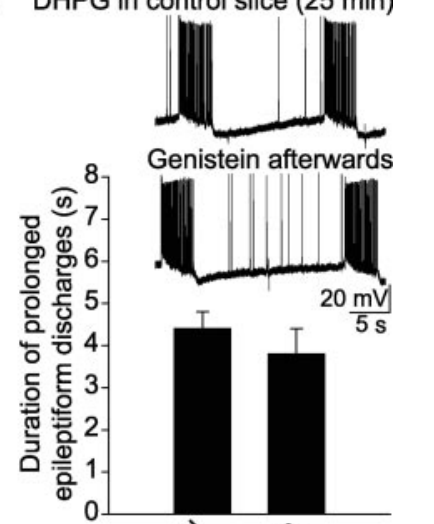

D

DHPG in PP2-pretreated slices

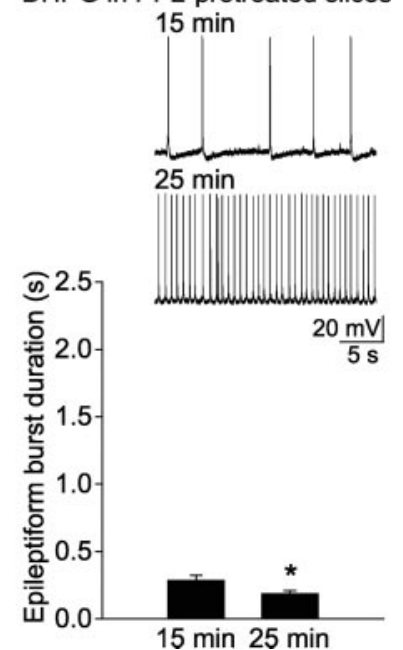

Figure 4. Inhibitors of tyrosine kinase prevent the generation of prolonged epileptiform discharges. $A$, Genistein $(30 \mu \mathrm{M})$, a broad-spectrum tyrosine kinase inhibitor, introduced $45 \mathrm{~min}$ before adding DHPG, prevented the appearance of prolonged epileptiform discharges. DHPG still accelerated the frequency of short epileptiform bursts (top, on average from $0.11 \pm 0.02 \mathrm{~Hz}$ at $15 \mathrm{~min}$ of DHPG to $0.36 \pm 0.06 \mathrm{~Hz}$ at $25 \mathrm{~min}$ of DHPG; $n=8 ; p<0.01)$. The burst duration at $25 \mathrm{~min}$ of DHPG $(0.163 \pm 0.023 \mathrm{sec})$ was significantly shorter than that at $15 \mathrm{~min}$ DHPG $\left(0.288 \pm 0.030 \mathrm{sec} ; n=8 ;{ }^{*} p<0.01\right)$. $B$, Genistein applied after the appearance of DHPGmediated prolonged epileptiform discharges did not affect the occurrence of the events ( $25 \mathrm{~min}$ DHPG, $4.4 \pm 0.4 \mathrm{sec} ; 30$ min after genistein addition, $3.8 \pm 0.6 \mathrm{sec} ; n=6 ; p=0.25)$. $C$, In contrast to genistein, pretreatment of slices with its inactive analog, genistin ( $30 \mu \mathrm{m} ; 45 \mathrm{~min}$ ), did not prevent the induction of prolonged epileptiform discharges by DHPG (epileptiform burst duration at $15 \mathrm{~min}, 0.352 \pm 0.046 \mathrm{sec}$; at $25 \mathrm{~min}, 1.687 \pm 0.197 \mathrm{sec} ; n=4 ;{ }^{*} p<0.01$ ). $D$, Similar to genistein, pretreatment with the selective Src-family tyrosine kinase inhibitor PP2 (10 $\mu \mathrm{m} ; 45 \mathrm{~min}$ ) prevented the induction of prolonged epileptiform discharges by DHPG. Short epileptiform bursts were still induced (top) and their duration decreased from $0.282 \pm 0.043$ $\sec (15 \mathrm{~min})$ to $0.184 \pm 0.024 \sec \left(25 \mathrm{~min} ; n=3 ;{ }^{*} p<0.05\right)$. The frequency of the short epileptiform bursts increased from $0.09 \pm 0.03 \mathrm{~Hz}$ at $15 \mathrm{~min}$ of DHPG to $0.44 \pm 0.10 \mathrm{~Hz}$ at 25 min of DHPG $(n=3 ; p<0.05)$. The presence of tyrosine kinase inhibitors did not affect the duration of short epileptiform bursts at $15 \mathrm{~min}$ (compared with control at $15 \mathrm{~min}$ : genistein, $p=0.23 ; P P 2, p=0.36)$.

significant difference in the short epileptiform burst frequency observed in the presence of either the MEK inhibitors (PD98059; U0126) or the tyrosine kinase inhibitors (genistein; PP2) at $25 \mathrm{~min}$ of DHPG.

Signaling pathways underlying DHPG-mediated ERK1/2 phosphorylation

DHPG-mediated phosphorylation of ERK1/2 was examined under two conditions: in the absence of ionotropic glutamate receptor (iGluR) inhibitors and TTX (ACSF) and in the presence of iGluR inhibitors and TTX (blockers).

As shown previously (Fig. 3A), DHPG elicited increases in phospho-ERK1/2 level in the presence of blockers (Fig. $5 A b, c$ ). In the absence of blockers (ACSF), an additional increase in the peak level of ERK1/2 phosphorylation was induced by DHPG (Fig. $5 A a, c)$ over that observed in the blockers.

When slices were pretreated with genistein (30 $\mu \mathrm{M} ; 45 \mathrm{~min})$, DHPG exposure in the presence of blockers no longer caused increases in ERK1/2 phosphorylation (Fig. 5Bb,c). However, with pretreatment with genistein in the absence of blockers (ACSF), ERK1/2 phosphorylation was again elevated by DHPG (Fig. $5 B a, c)$. In addition, we observed that, although the MEK inhibitors PD98059 and U0126 suppressed the baseline phosphorylation of ERK1/2 (Fig. 2E), treatment of slices with genistein did not affect the baseline phosphorylation of ERK1/2 (102 $\pm 7 \%$ of control; $n=4 ; p>0.05$ ).

DHPG-mediated ERK1/2 phosphorylation persisted in slices pretreated with chelerythrine $(10 \mu \mathrm{M})$ in the presence of blockers (Fig. $5 C b, c)$. These data are consistent with those obtained in slices pretreated with Gö6983 in the presence of blockers, in which a significant increase in ERK1/2 phosphorylation was induced by DHPG (Fig. 3D). Additional data in Figure $5 C c$ show that with chelerythrine pretreatment, DHPG induced comparable increases in the peak ERK1/2 phosphorylation under the ACSF and blocker conditions.

\section{Discussion}

This study shows that ERK1/2 activation is required for the induction of group I mGluR-mediated prolonged epileptiform discharges. ERK1/2 activation as well as the elicitation of prolonged epileptiform discharges appear to be mediated via a tyrosine kinase-dependent signaling pathway.

\section{Signaling pathways underlying group I mGluR-mediated ERK1/2 activation}

Consistent with recent data on hippocampal glial cells (Peavy and Conn, 1998), our results point to the activation of tyrosine kinase as a signaling step coupling group I mGluRs to ERK1/2 phosphorylation. In addition, group I mGluRs can be coupled to ERK1/2 via a protein kinase C-dependent pathway (Roberson et al., 1999). This PKC-dependent pathway has been shown to be activated via stimulation of group I mGluRs (Roberson et al., 1999) and of NMDA receptors (English and Sweatt, 1996). Our data suggest that a component of the DHPG-induced ERK1/2 phosphorylation is mediated by the elevation of neuronal activities after receptor stimulation. Thus, a component of the DHPGinduced phospho-ERK increase was suppressed in the presence of iGluR inhibitors and TTX (Fig. 5A). This "activity-dependent" component of DHPG-induced ERK1/2 phosphorylation is apparently dependent on PKC signaling, because it no longer appeared in slices pretreated with chelerythrine (Fig. 5C).

The lack of effect of PKC inhibitors (Gö6983, chelerythrine) on the induction of group I mGluR-mediated prolonged epileptiform discharges suggests that the PKC-dependent pathway does not play a critical role in this response. It is possible that the PKCand tyrosine kinase-dependent pathways coupling group I mGluRs to ERK1/2 phosphorylation are differentially engaged to 
bring about different forms of synaptic modification. The data obtained in slices pretreated with genistein (a tyrosine kinase inhibitor) are consistent with this notion. Genistein inhibited the DHPGmediated ERK1/2 phosphorylation in the presence of blockers and prevented the induction of prolonged epileptiform discharges. However, significant stimulation of ERK1/2 by DHPG in genistein-pretreated slices persisted in ACSF (Fig. 5B). Additional data suggest that this latter component of DHPG-induced ERK1/2 phosphorylation was not effective in initiating the prolonged epileptiform discharges (Fig. 4A). Separate effects of ERK1/2 phosphorylation dependent on the pathways of activation has been described in other cell types (York et al., 1998; Schmidt et al., 2000; Mochizuki et al., 2001). In addition, recent studies in the hippocampus show that ERK1/2 activation via Rap1 may be specifically involved in the long-term potentiation (LTP) of the CA1 synapses elicited by theta-burst stimulation of the afferent fibers and that different forms of LTP in the CA1 cells may require different pools of p42/44 MAPK (Morozov et al., 2003).

Activation of group I mGluRs, in particular mGluR5, causes the desensitization of the receptor through phosphorylation by PKC (Gereau and Heinemann, 1998). In view of this property, the lack of significant effects of PKC inhibitors on the epileptiform bursts, which are observed in the tonic presence of DHPG is somewhat unexpected (Fig. 3). Possibly, maximal activation by DHPG of the cellular events underlying the epileptiform burst can be elicited by the stimulation of a fraction of the available receptors and the associated signaling cascade. Thus, an increase in the available functional receptors by removing the $\mathrm{PKC}$-mediated desensitization during tonic agonist activation would not lead to an increase of the response level (spare receptor theory; Brown and Goldstein, 1986). The validity of this assumption requires additional testing.

\section{ERK1/2 and epilepsy}

Our data indicate that of the two forms of epileptiform bursts, only the induction of prolonged epileptiform discharges is sensitive to ERK1/2 inhibitors. Short epileptiform, interictal-like bursts appear to be ERK1/2 independent. It is possible that the cellular events elicited by DHPG for the induction of short epileptiform bursts are mediated by signaling steps involving group I mGluR stimulation and the associated G-protein activation. For example, suppression of the background leak conductance (Guerineau et al., 1994; Chuang et al., 2002) and of the slow afterhyperpolarization (Cohen et al., 1999) in hippocampal pyramidal cells appears to arise from a direct action of G-protein subunits. Generation of prolonged epileptiform bursts may require signaling processes downstream from G-protein activation (Chuang et al., 2001) involving ERK1/2 phosphorylation as an intermediate step.
Previous studies have shown that epileptiform activities in various experimental models are associated with alterations in the level of MAPK phosphorylation (Garrido et al., 1998; Mielke et al., 1999; Tian et al., 2000). In addition, it has been shown that inhibition of the ERK1/2 pathway attenuates the frequency and duration of epileptiform discharges (Murray et al., 1998; Sanna et al., 2000). However, available data also suggested that the suppression of ERK1/2 activities in the pilocarpine-model of epilepsy did not prevent seizures (Berkeley et al., 2002). Thus, it is not clear from these studies whether ERK1/2 activation is necessary for the induction of epileptiform discharges or whether the ERK1/2 activation is the consequence of neuronal activities (Bading et al., 1993; Rosen et al., 1994; English and Sweatt, 1996) associated with epileptiform discharges. In this study, in which prolonged epileptiform discharges were induced by the stimulation of group I mGluRs, ERK1/2 activation was found to be necessary for the induction of these discharges. Three lines of evidence support this inference. (1) Peak activation of ERK1/2 by group I mGluR stimulation (occurring at $\sim 5$ min after agonist application) (Fig. $3 A$ ) preceded the appearance of prolonged epileptiform discharges (at least $20 \mathrm{~min}$ after agonist application) (Fig. 1A,B). (2) The component of the DHPG-mediated ERK1/2 phosphorylation necessary for the induction of prolonged epileptiform discharges persisted in slices pretreated with iGluR inhibitors and TTX in which neuronal firing was suppressed (Figs. 3A, 5A). (3) Pretreatment of slices with inhibitors of ERK1/2 activation (PD98059 or U0126) prevented the appearance of prolonged epileptiform discharges (Fig. $2 A, B, D)$. Because these inhibitors suppressed both the basal level of ERK1/2 phosphorylation and the elevation of ERK1/2 phosphoryla- 
tion by group I mGluR stimulation (Fig. 2E), it is unclear which of their effects blocks the induction of prolonged epileptiform discharges. Additional data suggest that at least the elevation of ERK1/2 phosphorylation is necessary. Genistein did not affect the baseline activity of ERK1/2 significantly, yet the agent blocked the elevation of ERK1/2 phosphorylation after group I mGluR stimulation (Fig. $5 B b, c$ ) and prevented the induction of prolonged epileptiform discharges (Fig. $4 A$ ).

\section{References}

Abe T, Sugihara H, Nawa H, Shigemoto R, Mizuno N, Nakanishi S (1992) Molecular characterization of a novel metabotropic glutamate receptor mGluR5 coupled to inositol phosphate/ $\mathrm{Ca}^{2+}$ signal transduction. J Biol Chem 267:13361-13368.

Akiyama T, Ishida J, Nakagawa S, Ogawara H, Watanabe S, Itoh N, Shibuya M, Fukami Y (1987) Genistein, a specific inhibitor of tyrosine-specific protein kinases. J Biol Chem 262:5592-5595.

Anwyl R (1999) Metabotropic glutamate receptors: electrophysiological properties and role in plasticity. Brain Res Brain Res Rev 29:83-120.

Bading H, Ginty DD, Greenberg ME (1993) Regulation of gene expression in hippocampal neurons by distinct calcium signaling pathways. Science 260:181-186.

Bandrowski AE, Huguenard JR, Prince DA (2003) Baseline glutamate levels affect group I and II mGluRs in layer V pyramidal neurons of rat sensorimotor cortex. J Neurophysiol 89:1308-1316.

Berkeley JL, Levey AI (2003) Cell-specific extracellular signal-regulated kinase activation by multiple $\mathrm{G}$ protein-coupled receptor families in hippocampus. Mol Pharmacol 63:128-135.

Berkeley JL, Decker MJ, Levey AI (2002) The role of muscarinic acetylcholine receptor-mediated activation of extracellular signal-regulated kinase 1/2 in pilocarpine-induced seizures. J Neurochem 82:192-201.

Bortolotto ZA, Bashir ZI, Davies CH, Collingridge GL (1994) A molecular switch activated by metabotropic glutamate receptors regulates induction of long-term potentiation. Nature 368:740-743.

Brown JH, Goldstein D (1986) Differences in muscarinic receptor reserve for inhibition of adenylate cyclase and stimulation of phosphoinositide hydrolysis in chick heart cells. Mol Pharmacol 30:566-570.

Chang L, Karin M (2001) Mammalian MAP kinase signalling cascades. Nature 410:37-40.

Chen X, Bianchi R, Wong RKS (1998) Involvement of protein kinase C in mGluR-mediated oscillatory activity in the guinea pig hippocampus. Soc Neurosci Abstr 24:1088.

Chuang SC, Bianchi R, Kim D, Shin H, Wong RKS (2001) Group I metabotropic glutamate receptors elicit epileptiform discharges in the hippocampus through PLC $\beta 1$ signaling. J Neurosci 21:6387-6394.

Cohen AS, Coussens CM, Raymond CR, Abraham WC (1999) Long-lasting increase in cellular excitability associated with the priming of LTP induction in rat hippocampus. J Neurophysiol 82:3139-3148.

English JD, Sweatt JD (1996) Activation of p42 mitogen-activated protein kinase in hippocampal long term potentiation. J Biol Chem 271:24329-24332.

Ferraguti F, Baldani-Guerra B, Corsi M, Nakanishi S, Corti C (1999) Activation of the extracellular signal-regulated kinase 2 by metabotropic glutamate receptors. Eur J Neurosci 11:2073-2082.

Garrido YC, Sanabria ER, Funke MG, Cavalheiro EA, Naffah-Mazzacoratti MG (1998) Mitogen-activated protein kinase is increased in the limbic structures of the rat brain during the early stages of status epilepticus. Brain Res Bull 47:223-229.

Gereau RW, Heinemann SF (1998) Role of protein kinase C phosphorylation in rapid desensitization of metabotropic glutamate receptor 5 . Neuron 20:143-151.

Grewal SS, York RD, Stork PJ (1999) Extracellular-signal-regulated kinase signalling in neurons. Curr Opin Neurobiol 9:544-553.

Gschwendt M, Dieterich S, Rennecke J, Kittstein W, Mueller HJ, Johannes FJ (1996) Inhibition of protein kinase C mu by various inhibitors: differentiation from protein kinase C isoenzymes. FEBS Lett 392:77-80.

Guerineau NC, Gahwiler BH, Gerber U (1994) Reduction of resting K ${ }^{+}$ current by metabotropic glutamate and muscarinic receptors in rat CA3 cells: mediation by G-proteins. J Physiol (Lond) 474:27-33.
Gutkind JS (2000) Regulation of mitogen-activated protein kinase signaling networks by G protein-coupled receptors. Sci STKE 2000:RE1.

Gutkind JS, Novotny EA, Brann MR, Robbins KC (1991) Muscarinic acetylcholine receptor subtypes as agonist-dependent oncogenes. Proc Nat Acad Sci USA 88:4703-4707.

Hamakawa T, Woodin MA, Bjorgum MC, Painter SD, Takasaki M, Lukowiak K, Nagle GT, Syed NI (1999) Excitatory synaptogenesis between identified Lymnaea neurons requires extrinsic trophic factors and is mediated by receptor tyrosine kinases. J Neurosci 19:9306-9312.

Hazzalin CA, Mahadevan LC (2002) MAPK-regulated transcription: a continuously variable gene switch? Nat Rev Mol Cell Biol 3:30-40.

Huber KM, Kayser MS, Bear MF (2000) Role for rapid dendritic protein synthesis in hippocampal mGluR-dependent long-term depression. Science 288:1254-1257.

Johnson GL, Vaillancourt RR (1994) Sequential protein kinase reactions controlling cell growth and differentiation. Curr Opin Cell Biol 6:230-238.

Lee AC, Wong RK, Chuang SC, Shin HS, Bianchi R (2002) Role of synaptic metabotropic glutamate receptors in epileptiform discharges in hippocampal slices. J Neurophysiol 88:1625-1633.

Lin TA, Kong X, Haystead TA, Pause A, Belsham G, Sonenberg N, Lawrence Jr JC (1994) PHAS-I as a link between mitogen-activated protein kinase and translation initiation. Science 266:653-656.

Masu M, Tanabe Y, Tsuchida K, Shigemoto R, Nakanishi S (1991) Sequence and expression of a metabotropic glutamate receptor. Nature 349:760-765.

Merlin LR, Wong RK (1997) Role of group I metabotropic glutamate receptors in the patterning of epileptiform activities in vitro. J Neurophysiol 78:539-544.

Merlin LR, Bergold PJ, Wong RK (1998) Requirement of protein synthesis for group I mGluR-mediated induction of epileptiform discharges. J Neurophysiol 80:989-993.

Mielke K, Brecht S, Dorst A, Herdegen T (1999) Activity and expression of JNK1, p38 and ERK kinases, c-Jun N-terminal phosphorylation, and $\mathrm{c}$-jun promoter binding in the adult rat brain following kainate-induced seizures. Neuroscience 91:471-483.

Mochizuki N, Yamashita S, Kurokawa K, Ohba Y, Nagai T, Miyawaki A, Matsuda M (2001) Spatio-temporal images of growth-factor-induced activation of Ras and Rap1. Nature 411:1065-1068.

Morozov A, Muzzio IA, Bourtchouladze R, Van Strien N, Lapidus K, Yin D, Winder DG, Adams JP, Sweatt JD, Kandel ER (2003) Rap1 couples cAMP signaling to a distinct pool of p42/44MAPK regulating excitability, synaptic plasticity, learning, and memory. Neuron 39:309-325.

Murray B, Alessandrini A, Cole AJ, Yee AG, Furshpan EJ (1998) Inhibition of the p44/42 MAP kinase pathway protects hippocampal neurons in a cell-culture model of seizure activity. Proc Natl Acad Sci USA 95:11975-11980.

Pearson G, Robinson F, Beers GT, Xu BE, Karandikar M, Berman K, Cobb MH (2001) Mitogen-activated protein (MAP) kinase pathways: regulation and physiological functions. Endocr Rev 22:153-183.

Peavy RD, Conn PJ (1998) Phosphorylation of mitogen-activated protein kinase in cultured rat cortical glia by stimulation of metabotropic glutamate receptors. J Neurochem 71:603-612.

Post GR, Brown JH (1996) G protein-coupled receptors and signaling pathways regulating growth responses. FASEB J 10:741-749.

Raymond CR, Thompson VL, Tate WP, Abraham WC (2000) Metabotropic glutamate receptors trigger homosynaptic protein synthesis to prolong long-term potentiation. J Neurosci 20:969-976.

Roberson ED, English JD, Adams JP, Selcher JC, Kondratick C, Sweatt JD (1999) The mitogen-activated protein kinase cascade couples PKA and PKC to cAMP response element binding protein phosphorylation in area CA1 of hippocampus. J Neurosci 19:4337-4348.

Rosen LB, Ginty DD, Weber MJ, Greenberg ME (1994) Membrane depolarization and calcium influx stimulate MEK and MAP kinase via activation of Ras. Neuron 12:1207-1221.

Sanna PP, Berton F, Cammalleri M, Tallent MK, Siggins GR, Bloom FE, Francesconi W (2000) A role for Src kinase in spontaneous epileptiform activity in the CA3 region of the hippocampus. Proc Natl Acad Sci USA 97:8653-8657. 
Schmidt M, Goebeler M, Posern G, Feller SM, Seitz CS, Brocker EB, Rapp UR,Ludwig S (2000) Ras-independent activation of the Raf/MEK/ERK pathway upon calcium-induced differentiation of keratinocytes. J Biol Chem 275:41011-41017.

Taylor GW, Merlin LR, Wong RK (1995) Synchronized oscillations in hippocampal CA3 neurons induced by metabotropic glutamate receptor activation. J Neurosci 15:8039-8052.

Tian D, Litvak V, Lev S (2000) Cerebral ischemia and seizures induce tyrosine phosphorylation of PYK2 in neurons and microglial cells. J Neurosci 20:6478-6487.

Watabe AM, Carlisle HJ, O’Dell TJ (2002) Postsynaptic induction and presynaptic expression of group $1 \mathrm{mGluR}$-dependent LTD in the hippocampal CA1 region. J Neurophysiol 87:1395-1403.
Weiler IJ, Greenough WT (1993) Metabotropic glutamate receptors trigger postsynaptic protein synthesis. Proc Natl Acad Sci USA 90:7168-7171.

Weiss FU, Daub H, Ullrich A (1997) Novel mechanisms of RTK signal generation. Curr Opin Genet Dev 7:80-86.

York RD, Yao H, Dillon T, Ellig CL, Eckert SP, McCleskey EW, Stork PJ (1998) Rap1 mediates sustained MAP kinase activation induced by nerve growth factor. Nature 392:622-626.

Young D, Waitches G, Birchmeier C, Fasano O, Wigler M (1986) Isolation and characterization of a new cellular oncogene encoding a protein with multiple potential transmembrane domains. Cell 45:711-719.

Zhao W, Wong RKS (2003) Pyk2/Src are involved in the induction of group I mGluR-mediated icta-like discharges in hippocampus. Soc Neurosci Abstr 29:574.3. 